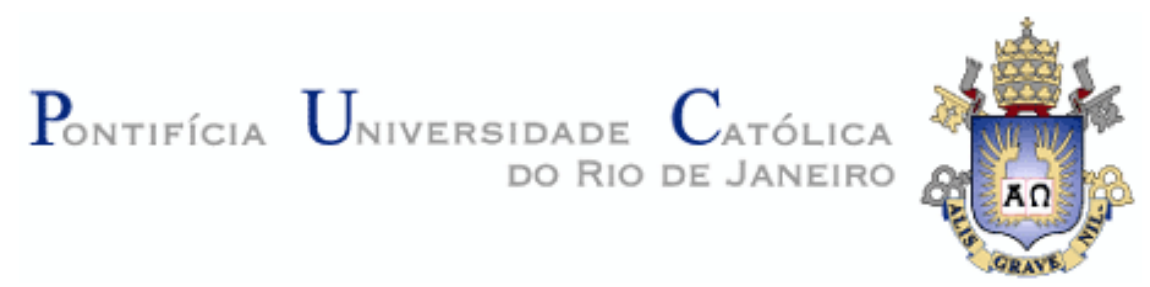

Fernando de Oliveira Teixeira da Silva

\author{
VALE QUANTO PESA? \\ Reforma trabalhista no Brasil sob a \\ mediação do valor-trabalho
}

Dissertação de Mestrado

Dissertação apresentada ao Programa de PósGraduação em Serviço Social da PUC-Rio como requisito parcial para obtenção do título de Mestre em Serviço Social.

Orientadora: Inez Terezinha Stampa

Rio de Janeiro Junho de 2011 


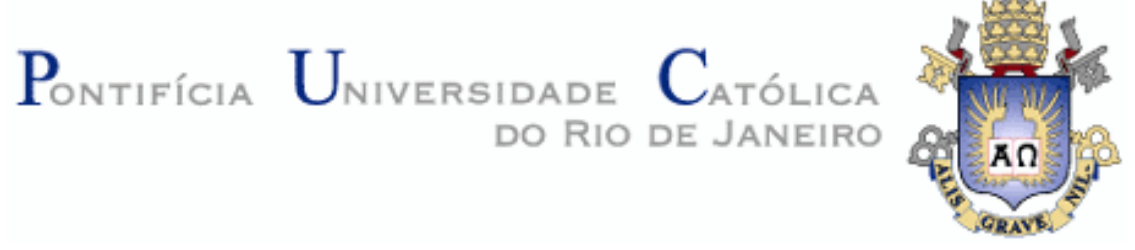

Fernando de Oliveira Teixeira da Silva

\title{
VALE QUANTO PESA? \\ Reforma trabalhista no Brasil sob a mediação do valor-trabalho
}

Dissertação apresentada como requisito parcial para obtenção do grau de Mestre pelo Programa de Pós-Graduação em Serviço Social do Departamento de Serviço Social do Centro de Ciências Sociais da PUC-Rio. Aprovada pela Comissão Examinadora abaixo assinada.

\author{
Prof ${ }^{a}$. Inez Terezinha Stampa \\ Orientador \\ Departamento de Serviço Social - PUC-Rio \\ Prof. Rafael Soares Gonçalves \\ Departamento de Serviço Social - PUC-Rio
}

Prof. Mauricio Mello Vieira Martins UFF

Profa . Mônica Herz

Vice-Decana de Pós-Graduação do Centro de Ciências Sociais - PUC-Rio

Rio de Janeiro, 13 de junho de 2011 
Todos os direitos reservados. É proibida a reprodução total ou parcial do trabalho sem autorização da universidade, do autor e da orientadora.

\title{
Fernando de Oliveira Teixeira da Silva
}

Graduou-se em Ciências Sociais pela Universidade Federal Fluminense (2008). Atualmente é estudante do "Programa Latinoamericano de Educación a Distancia en Ciencias Sociales" (PLED) do Centro Cultural de la Cooperación "Floreal Gorini", nos cursos "Problemas Contemporáneos de la Teoría Marxista" e "Economía política marxista". Participou, como pesquisador, do "Observatório Fundiário Fluminense", da Universidade Federal Fluminense. Tem experiência na área de Sociologia, com ênfase em estudos sobre o Trabalho.

Ficha Catalográfica

\begin{abstract}
Silva, Fernando de Oliveira Teixeira da
Vale quanto pesa? Reforma trabalhista no Brasil sob a mediação do valor-trabalho / Fernando de Oliveira Teixeira da Silva; orientadora: Inez Terezinha Stampa. - 2011.

111 f. : il. ; $30 \mathrm{~cm}$

Dissertação (mestrado)-Pontifícia Universidade Católica do Rio de Janeiro, Departamento de Serviço Social, 2011.

Inclui bibliografia.

1. Serviço social - Teses. 2. Trabalho. 3. Reforma trabalhista. 4. Teoria do valor-trabalho. 5. Reestruturação produtiva. 6. Precarização do trabalho. I. Stampa, Inez Terezinha. II. Pontifícia Universidade Católica do Rio de Janeiro. Departamento de Serviço Social. III. Título.
\end{abstract}

CDD: 361 


\section{Agradecimentos}

A Jorge e Siléa, por serem minha primeira e maior referência na vida e por sua sabedoria e amor, que levo comigo em todas as minhas jornadas.

À Keila, minha companheira em todos os sentidos, pelo amor, carinho, dedicação, ajuda e madrugadas compartilhadas, que foram necessários a este trabalho.

Aos companheiros e companheiras de militância pela consciência e prática formadoras, que foram e são fundamentais para os rumos deste trabalho. Em especial à Manuela Martins, pelo incentivo, por compartilhar súmulas e leis, além da amizade e presença constantes. E ao Vinícius Almeida, pela inquietante amizade e pela experiência militante.

Ao Rafael Barreto, companhia indispensável, por sua amizade e pelos animados debates filosófico-sambistas.

À PUC-Rio e à Capes, pela oportunidade, estrutura e auxílio financeiro.

Ao professor Rafael Gonçalves, pela disponibilidade, pelas contribuições, pelo ensino no curso deste mestrado.

Ao professor Maurício Vieira, por estar sempre disponível e acessível e pelo aprendizado e formação, que me acompanham desde a graduação.

À professora Inez Stampa, pelo conhecimento e orientação cedidos, liberdade, compreensão e paciência, que tornaram este trabalho possível e menos árduo. Agradeço também pela confiança e amizade. 


\section{Resumo}

Teixeira da Silva, Fernando de Oliveira; Stampa, Inez Terezinha. Vale Quanto Pesa? Reforma trabalhista no Brasil sob a mediação do valortrabalho. Rio de Janeiro, 2011. 111p. Dissertação de Mestrado Departamento de Serviço Social, Pontifícia Universidade Católica do Rio de Janeiro.

Este estudo busca analisar o processo de atualização da legislação do trabalho no Brasil, iniciado durante o primeiro governo de Fernando Henrique Cardoso e que se encontra ainda em curso no país, na forma de diversos projetos de lei e outros dispositivos que já alteraram ou pretendem alterar a legislação trabalhista. Pretende-se investigar se essas alterações, tanto as já realizadas como aquelas em fase de projeto, têm o sentido de institucionalizar práticas laborativas já vigentes, verificando a relação desse movimento com a necessidade de preservar a acumulação através do incremento das taxas de lucro e da extração da mais-valia. Dessa maneira pode-se analisar se o projeto de uma Reforma Trabalhista em curso no país se referiria a uma adequação legal à reestruturação da produção capitalista, que teve surto tardio no Brasil na década de 1990, o que significaria uma conformação a uma demanda capitalista tendo como objetivo facilitar a ampliação do capital. Para tanto, foi realizado um resgate conceitual da teoria do valor-trabalho e uma análise do atual contexto com referências no projeto neoliberal, entendido por seus defensores como o momento propício para a realização de alterações profundas nos direitos que dizem respeito às relações de trabalho. Nos dias de hoje, tem sido recorrente a afirmação de que a Reforma Trabalhista é uma necessidade, tendo em vista as transformações sociais e culturais, que teriam tornado a CLT obsoleta e caduca. Diante deste quadro político-ideológico, torna-se necessário resgatar a concepção de trabalho como base incontornável da vida social, bem como sua determinação como gerador de valor na economia capitalista.

\section{Palavras-chave}

Trabalho; Reforma Trabalhista; Teoria do Valor-Trabalho; Reestruturação Produtiva; Precarização do Trabalho. 


\section{Abstract}

Teixeira da Silva, Fernando de Oliveira; Stampa, Inez Terezinha (Advisor). Is It Worth the Cost? Labor reform in Brazil under the mediation of labor value theory. Rio de Janeiro, 2011. 111p. Master's Thesis - Departamento de Serviço Social, Pontifícia Universidade Católica do Rio de Janeiro.

This study has as its objective to analyze the process of actualization in the Brazilian labor laws, which started during Fernando Henrique Cardoso first term and is still taking place in the country today, in the form of a great diversity of bills and other initiatives that either have already changed or are intended to change the labor laws. It 's intended to investigate if these modifications - both the ones already accomplished and the ones in the project stage - are intended to institutionalize working practices that are already prevailing, checking the connections between this process and the demand for preserving the accumulation process that is made possible by raising the rates of profit and by increasing the exploration of the surplus value. Thereby it is possible to analyze if the current project of Labor Reform can be described as a legal adaptation to the capitalist productive restructuring that was a late process in Brazil and only took place from the 1990, which would mean a conformation to the capitalist demand. Therefore, it was necessary to make a conceptual investigation of the labor value theory and an analysis of a context distinguished by the neoliberal project and perceived as a suitable moment to make deep changes on work relations laws. Currently it is a common sense statement in Brazil that the Labor Reform is a necessity once we take into account the social and cultural transformations that have occurred in the last decades in the Brazilian society and that would make the "Consolidation of the Labor Legislation" outdated and obsolete. Considering this political and ideological context, it became necessary to recover the conception of labor as an inevitable basis of the social life as well as its quality as a value creator in a capitalist economy.

\section{Keywords}

Work; Labor Reform; Labor Theory of Value; Productive restructuring; Precarization of Work. 


\section{Sumário}

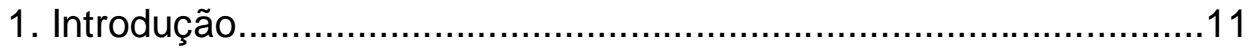

2. O trabalho como fundamento do valor............................................17

2.1. Marx e a crítica da economia política......................................17

2.2. Trabalho: ontologia do ser social...........................................20

2.3. Determinações da teoria do valor-trabalho...............................23

3. Reforma Trabalhista em tempos de crise do capital.........................31

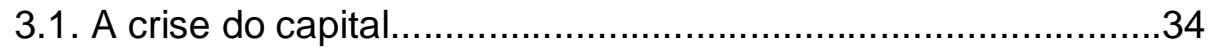

3.2. A chamada acumulação flexível.............................................39

3.3. Questão social e políticas sociais no neoliberalismo.................43

4. Legislação trabalhista: continuidades e descontinuidades...............52

4.1. O trabalho hoje: transformações em curso no país...................52

4.2. A normatividade do trabalho no Brasil recente........................62

5. A relação entre Reforma Trabalhista e a

Teoria do Valor-Trabalho..........................................................

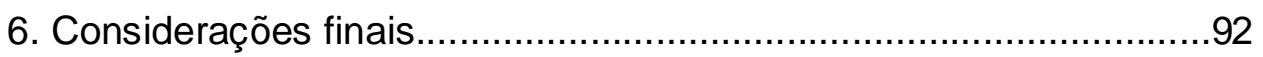

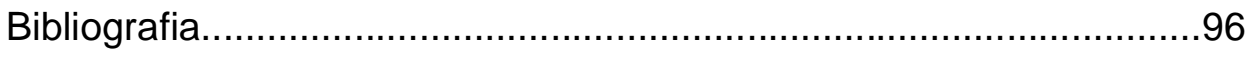

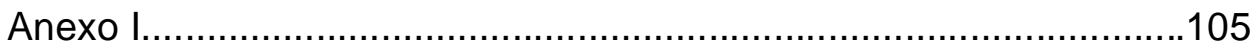

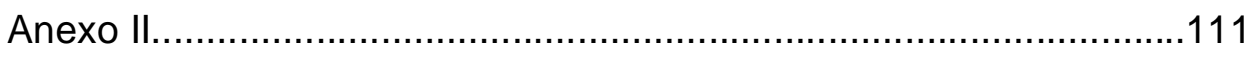




\section{Lista de Siglas}

CCJC - Comissão de Constituição, Justiça e Cidadania

CLT - Consolidação das Leis do Trabalho

CNT - Confederação Nacional do Transporte

CTASP - Comissão de Trabalho, de Administração e Serviço Público

CUT - Central Única dos Trabalhadores

DEM - Partido Democratas

DIEESE - Departamento Intersindical de Estatística e Estudos Sócioeconômicos

FAT - Fundo de Amparo ao Trabalhador

FGTS - Fundo de Garantia do Tempo de Serviço

FNT - Fórum Nacional do Trabalho

GTCL - Grupo de Trabalho para Consolidação das Leis

IBGE - Instituto Brasileiro de Geografia e Estatística

INCRA - Instituto Nacional de Colonização e Reforma Agrária

INSS - Instituto Nacional do Seguro Social

MP - Medida Provisória

MTE - Ministério do Trabalho e Emprego

OIT - Organização Internacional do Trabalho

PASEP - Programa de Formação do Patrimônio do Servidor Público

PDT - Partido Democrático Trabalhista

PEA - População Economicamente Ativa

PEC - Proposta de Emenda Constitucional

PIS - Programa de Integração Social

$\mathrm{PL}$ - Projeto de Lei

PP - Partido Progressista

PSB - Partido Socialista Brasileiro

PT - Partido dos Trabalhadores

PTB - Partido Trabalhista Brasileiro

PR - Partido da República

SAT - Seguro de Acidente de Trabalho

TST - Tribunal Superior do Trabalho 
Um homem se humilha Se castram seu sonho Seu sonho é sua vida E a vida é trabalho E sem o seu trabalho Um homem não tem honra E sem a sua honra Se morre, se mata Não dá pra ser feliz Não dá pra ser feliz.

Gonzaguinha 